\title{
Study of freight control systems for Arctic regions
}

\author{
Martin Grigoryan, and Evgenii Antipov \\ Admiral Makarov State University of Maritime and Inland Shipping, 5/7, Dvinskaya st., St. Petersburg, \\ 198035, Russia
}

\begin{abstract}
The paper presents the main results of the study of the cargo delivery control system in the Arctic zone. The authors hypothesized the need to generate information about the disadvantages of the cargo delivery control system in order to select and make effective decisions on changing this system. It is determined that the current control system has a number of problems that impede the management of cargo transportation, which require identification and updating of organizational and economic methods for their elimination due to the special interest in the Arctic at the current stage of its development. The study utilized the methods of applied sociology - the method of expert assessment with subsequent processing. A score scale with verbal characteristic was introduced, the use of which by expert respondents made it possible to quantify the significance of the disadvantages of the cargo delivery control system in the Arctic zone. The survey was conducted among experts from among forwarding operators carrying out specialized activities in the region, according to a pre-formed questionnaire. The results of the study show that the control quality is declining, as well as that the problems of controlling the cargo delivery to the Arctic zone are now quite relevant. The paper concludes on the need to develop organizational and economic methods to control the delivery of goods to the Arctic zone. Organizational and economic methods are proposed, in particular, the formation of a single transport operator of the Northern Supply Haul and a self-regulatory organization of forwarding operators.
\end{abstract}

\section{Introduction}

The Arctic is particularly interesting to domestic and foreign researchers, despite the low level of transport accessibility of most of its territories. This interest in this physical and geographical region of the Earth is explained by its unique natural complex and geopolitical significance. Numerous expeditions to the vast territories of the Far North were aimed at studying new territories [1], flora and fauna [2], indigenous peoples [3] and available resources [4]. At the current stage of Arctic development, the emphasis in research is shifted to technologies for the extraction of various resources and cargo delivery systems. Due to the geographical features of the Arctic, maritime transport occupies a leading place in the cargo delivery system.

Marine transport in the Arctic, in most cases, is uncontested in the development and supply of its vast territories. In the process of increasing its presence in the region, an appropriate port infrastructure was also created, providing all types of economic activities and protecting territories and waters. Accordingly, new or existing settlements were formed around infrastructure facilities, which provided for the activities of ports, industrial facilities, meteorological and research stations, military bases, border outposts and other facilities.

In the $20^{\text {th }}$ century, a serious alternative to water transport appeared - aviation, however, in terms of its carrying capacity and, most importantly, autonomy, air vehicles are significantly inferior to ships, and moreover, they are much more dependent on weather conditions [5]. Their operation requires the construction of runways and other related infrastructure. These circumstances became the main reasons for the predominance of maritime transportation in the northern regions, although aviation transport took its worthy place. This situation is likely to continue in the foreseeable future [6].

The $21^{\text {st }}$ century set a new trend in the development of transportation in the Arctic, it was determined by transporting oil, coal, coke, liquefied gas and other resources through the northern seas [12]. This required partial modernization of the existing and the creation of a new infrastructure complex of ports, attraction of additional investment in the region.

The issue of managing the supply of territories with products of various purposes through the delivery of goods by sea is still relevant. Especially for these purposes, during the USSR period the Northern Supply Haul was organized - a centralized control program for providing remote Arctic territories with a limited navigation period with the necessary products. Currently, the Northern Supply Haul in the Russian Federation has changed due to the implementation of the principle of decentralization of government bodies by regional affiliation. This led to many disadvantages in the cargo delivery control system.

The cargo delivery control system includes, among other things, state authorities of various levels. Accordingly, the Northern Supply Haul is financed through state contracts, and the executors of contractual 
obligations are forwarding operators who organize the delivery of goods to their destinations. It is obvious that the disadvantages of the cargo delivery control system have a full impact on freight forwarders and make it difficult or impossible for them to fully fulfill their contractual obligations.

Thus, a special interest in the Arctic determines the corresponding requirements for the quality of cargo delivery control. This fact indicates the relevance of the study of the control system of cargo delivery to the Arctic zone.

\section{Materials and Methods}

To identify the disadvantages of the cargo delivery control system in the Arctic areas, the authors consider it necessary to use applied sociology methods [7, 15], in particular, to conduct an expert survey among forwarding operators involved in the cargo delivery process within the Northern Supply Haul. The expert survey implies the establishment of clear boundaries of the studied object $[8,13]$, in connection with which, based on the described problems of the control system of cargo delivery in the Arctic zone let us present a further research program.

In general, the study included the following steps:

1) to determine the purpose (tasks) and content of the questionnaire;

2) to determine the criteria for selection of forwarding agents-respondents and their selection;

3) to organize the survey;

4) to choose methods for processing the obtained information and conduct the processing of the obtained results of the expert survey.

1. The general purpose of the study is to substantiate the nature of changes in the cargo delivery control system in the Arctic zone. The study was based on the hypothesis that it was necessary to generate information on the disadvantages of the cargo delivery control system in order to select and make effective decisions on changing this system.

Based on the analysis of the existing control system of cargo delivery to Arctic areas, the following disadvantages were identified:

- low level of infrastructure complex development, which includes unsatisfactory state of port facilities, water area and access roads;

- high degree of detachment from the process of goods delivery is interpreted as an insufficient level of involvement of the participants in the process itself;

- disorganization of the subordination structure, characterizes the degree of heterogeneity of the controlled system and its functional unsuitability;

- decentralization of the Northern Supply Haul, indicates an irrational distribution of functions for the organization of the Northern Supply Haul;

- incomplete requirements for forwarding operators during the Northern delivery, implies the absence of unified requirements for suppliers;
- low level of self-regulation of maritime transport in the Russian Arctic, implies the absence of non-state regulation of the Northern Supply Haul;

- untimely financing by the customer, which is interpreted as the satisfaction with the nature of mutual settlements of business entities with forwarding operators upon execution;

- low degree of consistency of operations performed by the participants in the process, implies a low level of quality of interaction between forwarding operators during the delivery process.

Expert respondent were asked to assess the presented disadvantages of the cargo delivery control system according to an 8-point scale based on their experience (Table 1).

Table 1. Scale of expert assessments with verbal characteristics

\begin{tabular}{|c|l|}
\hline Score & \multicolumn{1}{|c|}{ Verbal characteristics } \\
\hline 1 & Lowest priority \\
\hline 2 & Low priority \\
\hline 3 & Medium low priority \\
\hline 4 & Rather low than high priority \\
\hline 5 & Rather high than low priority \\
\hline 6 & Medium high priority \\
\hline 7 & High priority \\
\hline 8 & Highest priority \\
\hline
\end{tabular}

2. The criteria for selecting respondents are their experience and competence in organizing the transportation of goods. The experts are the representatives of top and middle management of forwarding organizations, which have been directly involved in the Northern Supply Haul over the past 5 years. Among forwarding organizations, those that have been delivering goods over the past 10 years and have port and (or) navigation funds have been selected. It is worth noting that the limited number of expert respondents is caused by the narrow focus of the study.

3. The survey is organized using the Internet, individually, via a dedicated channel in a cross-platform messenger in order to exclude group effects deforming the thinking of experts $[9,14]$.

4. The values of control system disadvantages were calculated on the basis of the points set by the experts (Table 1), with subsequent transformation into estimates by dividing the score by twice the sum of the number of disadvantages [10]. The average value of expert assessments of the disadvantages of the cargo delivery control system was calculated by the formula

$$
\omega_{i}=\frac{\mathrm{O}_{э i}}{\sum_{i=1}^{n} \mathrm{O}_{э i}}
$$

where $\mathrm{O}_{\ni i}$ - expert assessment of the disadvantages of the cargo delivery control system in accordance with the established scale, scores. 


\section{Results}

The results of the calculations are shown in Table 2. For the convenience of further analysis, let us present the average score graphically (Fig. 1).

The similarity of expert opinions was assessed by the Kedall formula [11]. The similarity coefficient was 0.59 and the critical point $\mathrm{T}_{\text {кр }}-0.54$. This ratio indicates that the respondents are competent in these matters and the results of the expert survey should be considered adequate.

The coefficient of variation of expert opinions was $43.8 \%$ and was calculated as the mean square deviation divided by the average arithmetic value of the averaged score values [14]. This also demonstrates the similarity of opinions of expert respondents.

Table 2. Research results of the cargo control system in the Arctic Zone

\begin{tabular}{|l|c|c|c|c|c|c|c|c|c|c|c|}
\hline \multirow{2}{*}{\multicolumn{1}{|c|}{ System disadvantage }} & \multicolumn{6}{|c|}{ Expert and the corresponding score } & $\begin{array}{c}\text { Average } \\
\text { score, } \\
\bar{\omega}_{i}\end{array}$ \\
\cline { 2 - 12 } & I & II & III & IV & V & VI & VII & VIII & IX & X \\
development of infrastructure & 0.111 & 0.028 & 0.083 & 0.083 & 0.056 & 0.083 & 0.083 & 0.083 & 0.028 & 0.083 & 0.020 \\
\hline $\begin{array}{l}\text { 2. High detachment from the } \\
\text { delivery process }\end{array}$ & 0.028 & 0.056 & 0.056 & 0.028 & 0.028 & 0.028 & 0.056 & 0.056 & 0.056 & 0.056 & 0.012 \\
\hline $\begin{array}{l}\text { 3. Disorganization of the } \\
\text { subordination structure }\end{array}$ & 0.083 & 0.111 & 0.111 & 0.056 & 0.083 & 0.111 & 0.111 & 0.028 & 0.111 & 0.139 & 0.026 \\
\hline $\begin{array}{l}\text { 4. Decentralization of the } \\
\text { Northern Supply Haul }\end{array}$ & 0.222 & 0.194 & 0.194 & 0.111 & 0.222 & 0.222 & 0.222 & 0.194 & 0.139 & 0.222 & 0.054 \\
\hline $\begin{array}{l}\text { 5. Incomplete vendor } \\
\text { requirements }\end{array}$ & 0.139 & 0.167 & 0.167 & 0.139 & 0.111 & 0.167 & 0.194 & 0.111 & 0.222 & 0.028 & 0.040 \\
\hline $\begin{array}{l}\text { 6. Low level of maritime self- } \\
\text { regulation in the Russian Arctic }\end{array}$ & 0.167 & 0.139 & 0.139 & 0.222 & 0.139 & 0.056 & 0.167 & 0.139 & 0.194 & 0.167 & 0.042 \\
\hline $\begin{array}{l}\text { 7. Delayed financing by the } \\
\text { customer }\end{array}$ & 0.194 & 0.222 & 0.222 & 0.194 & 0.167 & 0.194 & 0.139 & 0.222 & 0.167 & 0.194 & 0.053 \\
\hline $\begin{array}{l}\text { 8. Low consistency of activities } \\
\text { performed by process } \\
\text { participants }\end{array}$ & 0.056 & 0.083 & 0.028 & 0.167 & 0.194 & 0.139 & 0.028 & 0.167 & 0.083 & 0.111 & 0.029 \\
\hline
\end{tabular}

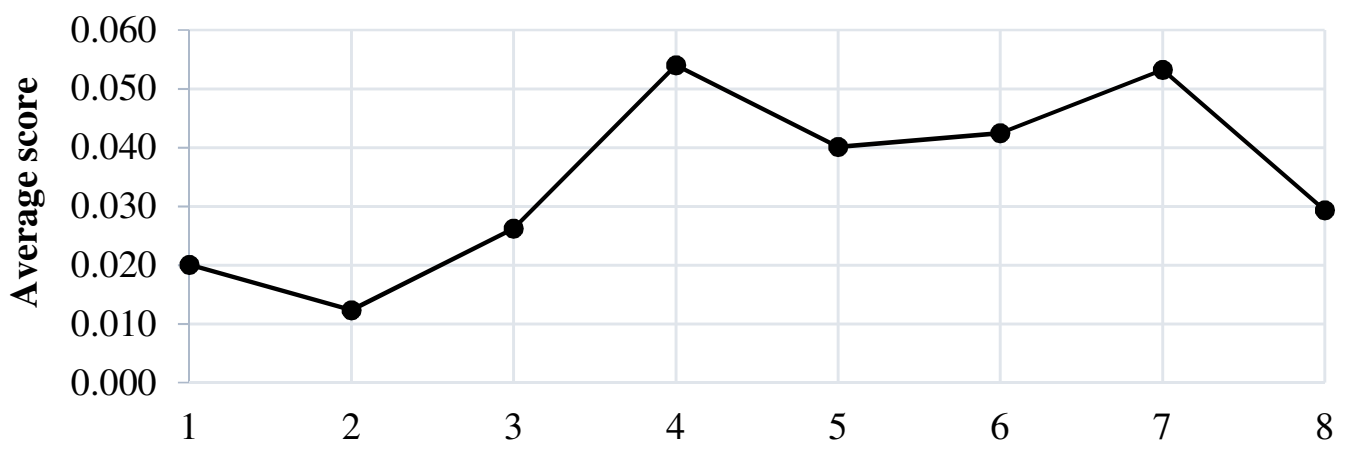

System disadvantage

Figure 1. Average score of disadvantages of the cargo delivery control system in the Arctic Zone

\section{Discussion}

According to experts (Table 2 and Fig. 1), the most significant disadvantages of the cargo delivery control system were the following: "Decentralization of the Northern Supply Haul" and "Delayed financing by the customer" (0.054 and 0.053 , respectively). Then, they are followed by "Low level of maritime self-regulation in the Russian Arctic" and "Incomplete vendor requirements" (average score -0.042 and 0.040, respectively); "Low consistency of activities per-formed by process participants" and "Disorganization of the subordination structure" (average score -0.029 and 0.026, respectively); "Low level of infrastructure development" and "High detachment from the delivery process" (average score -0.020 and 0.012 , respectively). The resulting hierarchy of disadvantages in the cargo delivery control system is shown in Table 3.

Disadvantages ranked from 5 to 8 as less significant are not further considered in the study.

The obtained results make it possible to assume that such a disadvantage as the decentralization of the Northern Supply Haul may be eliminated by organizing a single transport operator. The prerequisites are as follows:

1) structural changes of the organizational and economic mechanism of cargo delivery control system to the Arctic zone towards consolidation;

2) convenience of cargo delivery for freight forwarding operators, since the volumes of deliveries to the Arctic Zone are relatively small and it would be more 
rational to deliver combined consignments with their further distribution to the final destination points;

3) absence of a single budget of the Northern Supply Haul, which would allow the effective use of funds in the transportation of goods;
4) inadequate distribution of management functions according to the stages of the cargo delivery process within the Northern Supply Haul due to duplication of functions of some business entities and excessive conglomeration of control structures.

Table 3. Ranking of disadvantages of the cargo delivery control system in the Arctic Zone

\begin{tabular}{|l|c|c|}
\hline \multicolumn{1}{|c|}{ System disadvantage } & Average score, $\bar{\omega}_{i}$ & $\begin{array}{c}\text { Ranking, } \\
r_{i}\end{array}$ \\
\hline Decentralization of the Northern Supply Haul & 0.054 & 1 \\
\hline Delayed financing by the customer & 0.053 & 2 \\
\hline Low level of maritime self-regulation in the Russian Arctic & 0.042 & 3 \\
\hline Incomplete vendor requirements & 0.040 & 4 \\
\hline Low consistency of activities per-formed by process participants & 0.029 & 5 \\
\hline Disorganization of the subordination structure & 0.026 & 6 \\
\hline Low level of infrastructure development & 0.020 & 7 \\
\hline High detachment from the delivery process & 0.012 & 8 \\
\hline
\end{tabular}

\section{Conclusion}

Thus, the results of the study of the control system of cargo delivery to the regions of the Arctic Zone became the basis of the following provisions.

1. Currently, the problems of controlling the cargo delivery to the Arctic zone are key.

2. When organizing the delivery of goods to the Arctic Zone, the degree of centralization of transportation is important.

3. It is necessary to develop organizational and economic methods for managing the delivery of goods, in particular, to update the method consisting in the formation of a single transport operator of the Northern Supply Haul and the self-regulatory organization of forwarding operators. The inclusion of such elements as the unified transport operator of the Northern Supply Haul and the self-regulatory organization of forwarding operators in the mechanism for managing the delivery of goods to the Arctic zone will ensure the following:

- increase the budget effectiveness of the Northern Supply Haul;

- establish a unified criteria base for the selection of forwarding agents; Haul;

- establish the concept of the Northern Supply

- ensure polynomial delivery terms;

- improve the concurrency of transport participants;

- reduce management decision-making terms;

- increase the investment attractiveness of the water transport sub-sector in the Arctic Zone of the Russian Federation.

4. The results of the study may be used to design and adjust the program of initiated changes in the control system of cargo delivery to the Arctic Zone.

\section{References}

1. C. R. Markham, The Lands of Silence: A History of Arctic and Antarctic Exploration, (Cambridge
University Press, 2015) DOI: 10.1017/CBO9781107785410.

2. K. F. Drinkwater, F. J. Mueter and Sei-Ichi Saitoh, ICES Journal of Marine Science, 75 (7), 2293-2298, (2018). DOI: 10.1093/icesjms/fsy179.

3. D. Damas Arctic Migrants/Arctic Villagers: The Transformation of Inuit Settlement in the Central Arctic, (McGill-Queen's University Press, 2002). DOI: $10.2307 /$ j.ctt809qt.

4. S. V. Krivovichev Arctic Mineral Resources, Science and Technology, April. (2019). DOI: 10.3390/books978-3-03897-825-1.

5. $\quad$ S. B. Nelson, Airships in the Arctic, 46(3), 189292, (1993) DOI: 10.14430/arctic1353.

6. N.A. Pegin Arctic and North - interdisciplinary electronic scientific journal, 2 (23), (2016). DOI: 10.17238/issn2221-2698.2016.23.32.

7. R. Kalleberg and R. Kalleberg, Acta Sociologica, 43(4), 399-411. (2000). DOI: 10.1080/15579336.1973.11769584.

8. J. K. Hammitt. Y. Zhang, Risk Analysis, 33(1), 109-120, (2013). DOI: 10.1111/j.15396924.2012.01833.x.

9. L. Schwartz and G. Yovel, Journal of Vision, 17, 1001, (2017). DOI: 10.1167/17.10.1001.

10. L. Bornmann and W. Marx, Journal of Informetrics, 9 (2), 408-418, (2015) ISSN 17511577. DOI: 10.1016/j.joi.2015.01.006.

11. K. Kendall, M. Kendall, F. Rehfeldt, Adhesion of Cells, Viruses and Nanoparticles. (Springer, Dordrecht, 2010). DOI: 10.1007/978-90-4812585-2_7.

12. S. Agarcov, S. Kozmenko, A. Teslya, IOP Conf. Ser.: Earth Environ. Sci., 434, 012011, (2020). DOI: 10.1088/1755-1315/434/1/012011

13. E. E. Brent, Jr., University of Missouri-Columbia, Idea Works, 25(1), 31-59, (1996). DOI: 10.1177/0049124196025001002.

14. G. G. Stern, M. L. Stein, B. S. Bloom, American Journal of Sociology, 62 (2), 225-226, (1956). DOI: $10.1086 / 221973$. 
15. C. Cappell, D. Kamens, Teaching Sociology, 30 (4), 467-494, (2002). DOI:10.2307/3211505. 